\title{
The Influence of Self-esteem and Sense of Security to the Cognition of the Destructive Cult of College Students
}

\author{
Junqing Xin ${ }^{1}$, Baoxiang $\mathrm{Fan}^{2}, \mathrm{Han} \mathrm{Ji}^{1}, \&$ Bin $\mathrm{Li}^{1,2}$ \\ ${ }^{1}$ Business College of Beijing Union University, P. R. China \\ ${ }^{2}$ Center for the Study of Cultic Groups \& Religious Culture, Beijing Union University, P. R. China \\ Correspondence: Bin Li, Center for the Study of Cultic Groups \& Religious Culture, Beijing Union University, \\ 100101, P. R. China. E-mail: libinpsy@126.com
}

Received: June 13, 2019 Accepted: July 5, $2019 \quad$ Online Published: July 23, 2019

doi:10.5539/ass.v15n8p65 URL: https://doi.org/10.5539/ass.v15n8p65

This paper is phased research results supported by a Beijing social science fund research base project (No.14JDZHB008) and a social science plan project of Beijing Municipal Education Commission (No. SM201511417001).

\begin{abstract}
In this study, self-esteem scale (SES), Security Questionnaire (SQ) and cult susceptibility test questionnaire were used to investigate 350 college students in Beijing, and the results were analyzed to explore the influence of self-esteem and sense of security on college students' cognition on cults. The results indicate obvious differences in demographic variables and correlations among college students' self-esteem, their sense of security and their cognition on cults. In addition, due to the predictive functions of self-esteem and sense of security, the cult confusion among college students can be prevented by improving their self-esteem and sense of security by means of introspection, feedback from others and participation in practice.
\end{abstract}

Keywords: self-esteem, Sense of Security, cognition of the destructive cult

\section{The Research Background}

The cult organization is a society with anti-science, anti-human, anti-social, anti-government-based doctrines and practices that are socially harmful. The cult represented by Falun Gong hinders the development of human society. It is a public hazard that harms contemporary college students and impairs national social security. The group of college students is in the transitional period of the formation of world outlook on life and the maturity of psychological development. thus highlighting "governance" in the cult prevention work among college students can effectively prevent the occurrence of superstitious cult behavior.

The concept of self-esteem first appeared in the 1890s in William James' book Psychology Principle in which he proposed a formula "self-esteem=success/pretention". Stanley Coopersmith (1967) defined self-esteem as a personal aspect of his evaluation and usually held by an opinion of himself". Xiting Huang et al. (2003) believed that self-esteem, an emotional experience of dignity, self-love and self-respect, evolves on the basis of self-evaluations by individuals and in the meantime requests respect from others, groups and society. Maslow pointed out an individual experiences confidence, freedom and sense of security when escaping from a panic and a helpless anxiety, especially when his/her various needs, present or future are met. Having combined their own experience and related research abroad and absorbed Bush's term "control", Congzhong, Anli defined sense of security, suggesting that it is the premonition in a dangerous situation, physically or psychologically, and strong or weak sense of power when confronted by certain risks. Sense of security involves two dimensions - feeling of certainty and feeling of control, and has been proved to be positively correlated with level of self-esteem.

Thus, this study, we propose the following hypothesis:

(1) There was a significant difference in demographic variables among college students' self-esteem level, security and cult cognition respectively.

(2) There is a relationship among college students' self-esteem level, sense of security and their cognitive on cults. 
(3) College students' self-esteem and sense of security have predictive function on their cognition on cults.

(4) College students' sense of security plays an intermediary role between self-esteem and cognition on cults.

(5) The self-esteem of college students and sense of security at the same time play an intermediary role in the influence of the cognition on cult chain.

\section{The Object of Study}

This study adopts the method of stratified random sampling. 350 university students in Beijing, China, have been surveyed, among which one class was randomly chosen from 1 to 4 grade, and 333 valid questionnaires have been collected, indicating $95.1 \%$ effective rate.

\section{Research Tools and Methods}

\subsection{Self-esteem Scale (Self - esteem Scale, SES)}

The self-esteem scale complied in 1965 by Rosenberg were used to assess the participants on the overall feeling of self-worth, and self-acceptance. It contains a total of 10 topics (involving five positive score subject and 5 reverse score), the 1-4 level 4 points system, 1 represents totally not conforming, 2 representative not conforming, 3 means accordance, and 4 means great accordance). To let the participants do more conveniently and fluently, the questionnaire adopted reverse score by reversing the level 4 points system, so the higher the scores of scale, the lower self-esteem the respondent has.

\subsection{Security Scale (Security Questionnaire, $S Q$ )}

Security scale (Security Questionnaire, SQ) compiled by An li-juan (2003), compiled contains two dimensions human Security and certainty of control. The scale is composed of 16 topics, including questions 1, 3, 6, 8, 10, $12,15,16$ which are human Security dimension and questions 2, 4, 5, 7, 9, 11, 13, 14 which are about certainty of control. Those questions use 1-5 five points systems, and the higher the score of the individual means the higher sense of security. The scale is mainly used to test psychological characteristics of sense of security of normal people and patients with neurosis. Scale is suitable for applications in the researches of the college students and college students in China.

\subsection{Cult Susceptibility Test}

The test adopts self-report questionnaire with 16 questions. The more affirmative answers the respondents give, the higher risk of cult susceptibility.

\section{The Results and Discussion}

\subsection{Characteristics of College Students' Cognition on Cults}

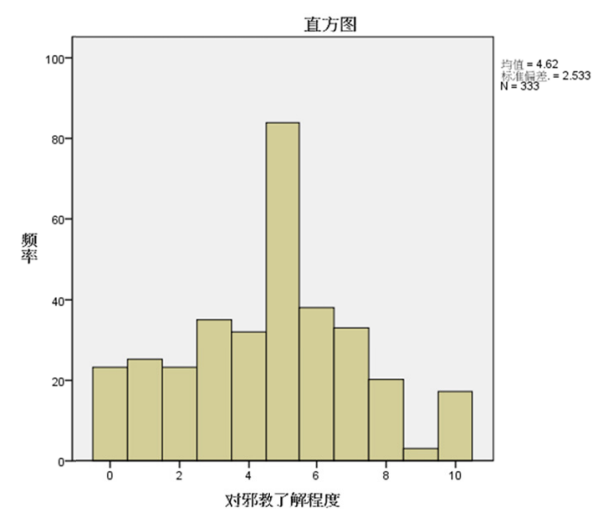

In the survey, college students were asked to rate their understanding of cult. The average is 4.62 , and scores are normally distributed ( 10 points are very understanding, 0 is very don't understand).

On college students' understanding of the basic characteristics of the cult, $81.6 \%$ of college students thought fabricating heterodox is its basic characteristics, $86.1 \%$ of college students chose the mind control, $69.3 \%$ thought leader worship, $64.5 \%$ thought cult collected money, $60.8 \%$ of college students choose the secret association.

On the understanding of major hazard of a cult, $91.9 \%$ of college students think that destroying the social harmony is a major hazard cult, $81.0 \%$ of students chose endangering state security, $77.7 \%$ of students choose to defraud money believers, $71.7 \%$ of the students chose to trample the faithful life. 
On the cult sect of specific cognitive, $98.2 \%$ of college students think that Falun gong is a cult, the proportion of college students is to identify several other denominations are: view sound practice (49.5\%), unified teaching (43.8\%), the Japanese Aum Doomsday cult (42.3\%), of the people's temple (39.3\%).

As to college students' cognitive mode of cult penetration, website, email, harassing phone calls are main ways of college students' understanding, accounting for 71.5\%; emotional solicitude with little mercy accounts for a $67.9 \%$; sending out posted on-campus cult materials $(63.4 \%)$, by the name of the student community transmission accounted for $59.5 \%$; infiltration in the name of the exit exchange learning abroad accounts for $51.7 \%$.

Predisposition to cult questionnaire analysis found that factors influence the grade $(\mathrm{F}=10.507$, the $\mathrm{SIG}<0.05)$, and its total score tends to increase year by year (see chart).

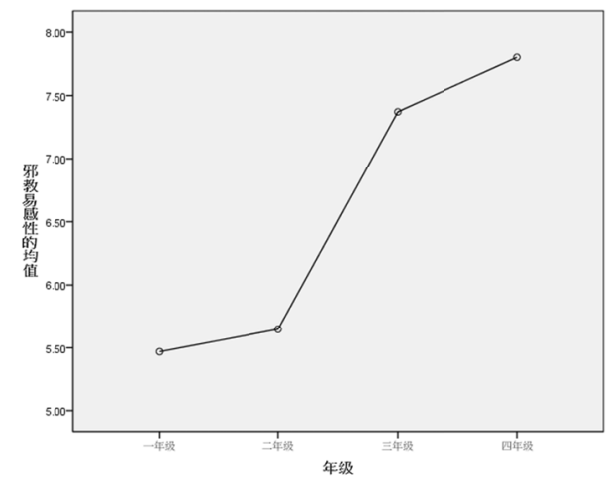

\subsection{College Students'Self-esteem, a Sense of Security and the Relationship Between Cognitive Cult}

Through analysis of self-esteem, a sense of security and its subscales (human security and control) and cult susceptibility related questionnaire (see table), self-esteem, sense of security are found to be negatively correlated with cult susceptibility, namely, the higher the level of self-esteem and sense of security, the lower the cult susceptibility.

Table 1 . The correlation between self-esteem and cult susceptibility

\begin{tabular}{|c|c|c|c|c|c|c|}
\hline & & security & Self-esteem & interpersonal & Control & Evil \\
\hline Self-esteem & Pearson correlation & $.503^{* *}$ & & & & \\
\hline interpersonal & Pearson correlation & $.956^{* *}$ & $.486^{* *}$ & & & \\
\hline Control & Pearson correlation & $.960^{* *}$ & $.469^{* *}$ & $.836^{* *}$ & & \\
\hline Evil & Pearson correlation & $-.288^{* *}$ & $-.163^{* *}$ & $-.240^{* *}$ & $-.298^{* *}$ & 1 \\
\hline
\end{tabular}

**. In. 01 level (double side).

\subsection{College Students'Self-esteem, a Sense of Security to the Cult of Cognitive Prediction Effect}

By using cult susceptibility as the dependent variable, self-esteem and a sense of security as independent variables and the linear regression, the sense of security especially, the factors of certainty of control has certain prediction effect on cult susceptibility.

Table 2 .

The model summary

\begin{tabular}{|c|c|c|c|c|c|c|c|}
\hline Model & $\mathrm{R}$ & $\mathrm{R}^{\wedge} 2$ & \multicolumn{2}{|c|}{ Adjust $\mathrm{R}^{\wedge} 2$} & The standard estimate e & & \\
\hline 1 & $.299^{\mathrm{a}}$ & .089 & \multicolumn{2}{|c|}{.081} & \multicolumn{2}{|l|}{2.94847} & \\
\hline \multicolumn{8}{|c|}{$\begin{array}{c}\text { a. Predicting variables: (constant), determine the sense of control, self-esteem and personal security. } \\
\text { coefficient }\end{array}$} \\
\hline \multirow{2}{*}{\multicolumn{3}{|c|}{ Model }} & & tion coefficient & standard coefficient & \multirow{2}{*}{$\mathrm{t}$} & \multirow{2}{*}{ Sig. } \\
\hline & & & B & Standard error & A trial version & & \\
\hline \multirow{4}{*}{1} & (cons & & 11.146 & 1.242 & & 8.974 & .000 \\
\hline & self-e & & -.021 & .043 & -.030 & -.490 & .624 \\
\hline & Human & & -.001 & .070 & -.001 & -.014 & .989 \\
\hline & Determine & ontrol & -.189 & .065 & -.282 & -2.904 & .004 \\
\hline
\end{tabular}

a. Dependent variable; cult susceptibility 


\section{Analysis and Countermeasures}

\subsection{The Basic Characteristics of College Students' Cognitive Cult}

From the survey data, college students have a clear basic understanding of cults. Most students understand the basic characteristics of cults and understand representative cults, such as Falun Gong. The channels of understanding are mostly network or electronic channels, and the susceptibility to cults is on rise.

\subsection{From the Angle of Improving Students' Self-esteem and Security to Prevention Cult Temptation}

The perspective of cult prevention is defined in two factors: the improvement of the level of self-esteem and the satisfaction of the sense of security, that is, from the perspective of "supporting the righteousness and evil spirits", improving the mental health of college students, and assisting college students in dealing with problems encountered in their study life. It is an important part of effectively preventing cults.

College students are in phase of youth, youth period was a period of rapid development of self-awareness, known as the "second birth" (E.S pranged, 1924), being born to live a life as opposed to being born to live in this world.

College students' self-consciousness began to differentiate, self-contradictions increasingly prominent, so that they live in the turmoil in the world of the restless psychological: self-affirmation and negation, self-worth and negation, gain and loss of self-esteem, self-confidence and inferiority, etc., college students need to establish the self-consistency, forming stable self-concept, eventually form the outlook on life, values and world view. After university life and education, the development of college students' self-consciousness reached a new level: independence, self-esteem, self-confidence, competitiveness gradually mature; Self-awareness, self-experience and self-control tend to be coordinated development; Core of self-consciousness, world outlook and outlook on life have been basically established. But this development is filled with a lot of contradictions: "subject I" and "the object I", "my ideal", and the contradiction between the "real me"; Self-assessment from time to time is objective and subjective, a high self-assessment (leads blindly optimistic, self-righteous, etc.) or low self-evaluation (self, self-doubt, etc.), control ability is relatively weak and so on.

Therefore, to enhance the level of college students' self-esteem and a sense of security, one can use the way of introspection in the first place. Self-evaluating is to examine their own thoughts and behavior, analyze yourself, find their own shortcomings and faults, and correct them immediately. People like a piece of natural ore, need to use a knife to carve continuously to get rid of dirt. Although the process is full of pain, but after we carve the ore it can be more glorious and become worthier. Self-examination process is the process of self-improvement. "Reflection" is the only way to success. Confucius said, "when we see a man of virtue and talent, we should think of equaling them; when we see a man of a contrary character, we should turn inwards and examine ourselves" (the analects of Confucius, the humanity), "Tseng Tzu said, "every day I examine myself on three points." (the analects of Confucius, learn and understand the introspection can grow and breed effective against evil.

In addition, through the method of social learning and by collecting feedback from others, it can also effectively improve the level of self-esteem. People are social animals, and it is impossible to live independently from others and collectively. Since living in a crowd, it is necessary to involve other people's attitudes and evaluations. Others are mirrors of self-reflection. From the feedback of others, we can know what the "I" is. What is the meaning of "I", the state of self and behavior are not appropriate, how to adapt to the situation, and where to improve. Most successful business people have this kind of commonality: the self in their own eyes and the eyes of others, the image is very close, and there is rarely a self-affirmation but not recognized by others. Because they are good at understanding and accepting other people's ideas, choosing good from them, constantly improving themselves according to the feedback of others, improving their work, thus forming a "virtuous circle" and finally achieving career success. Not all people are happy to accept negative feedback from the mirror of others. Some people are self-righteous, rejecting the negative comments of others or argue from the objective perspective, blaming on others. Therefore, it is difficult to improve themselves and obtain good interpersonal relationships and successful careers.

In addition, participating in the practice and then obtaining a successful experience is an effective way to improve self-esteem. Practice is the sole criterion for testing not only truth but also one's own understanding of himself. Life is a huge melting pot in which your capability can be tested, so that you can know yourself better through either failure or success. Don't stay in subjective evaluation, consciousness, only through the test of life is the real "true self".

In short, the Chinese psychologist Chong-de Lin (2003) argues that "mental health is much more than the 
absence of mental illness, and it is a positive state of mind. Mental health is a kind of subjective experience of the individual, including both positive emotion and negative emotion. It all aspects of the personal life, its core is "self-esteem. With the rise of positive psychology theory, more and more psychologists to eliminate mental illness mental health from a single dimension to both symptoms and double factors of psychological well-being, for positive mental health education and psychological quality education provide a theoretical basis. Mental health is to eliminate the negative mental health status and gain positive mental health status of collection. Enhancing college students' self-esteem and sense of security can be a precaution against cult penetration, and in contrast, pure "congesting or blocking" may result in rebellion among college students.

\section{References}

Fan, B. X., \& Li, B. (2018). A new perspective of destructive cult groups against. Science and Atheism.

Wang, Y. L., Li, B., \& Yan, N. (2016). College students' psychological quality training (3rd ed.). Beijing: Electronic Industry Press.

Xue, P., \& Fan, B. X. (2017). Cult spread under the Internet environment research. Science and Atheism.

\section{Copyrights}

Copyright for this article is retained by the author(s), with first publication rights granted to the journal.

This is an open-access article distributed under the terms and conditions of the Creative Commons Attribution license (http://creativecommons.org/licenses/by/4.0/). 